\title{
PERDARAHAN INTRASEREBRAL SEBAGAI KOMPLIKASI NEUROLOGI EMBOLI SEPTIK PADA ENDOKARDITIS INFEKTIF: SEBUAH LAPORAN KASUS
}

\author{
INTRACEREBRAL HEMORRHAGE AS A NEUROLOGICAL COMPLICATION \\ OF SEPTIC EMBOLISM IN INFECTIVE ENDOCARDITIS: A CASE REPORT
}

Mohammad Kurniawan, ${ }^{*}$ Salim Harris, ${ }^{*}$ Al Rasyid, ${ }^{*}$ Taufik Mesiano, ${ }^{*}$ Rakhmad Hidayat, ${ }^{*}$ Yesi Astri ${ }^{*}$

\begin{abstract}
Infective endocarditis (IE) is a life-threatening disease. The incidence of IE in developing countries is reported at 1.7-6.2 per 100,000 individuals per year. IE is also known as a potential condition for embolization, especially septic embolism to the brain. Septic embolism results in various neurological complications and manifestations due to vascular occlusion, aneurysm formation and rupture of the aneurysm. We report a case of 34-year-old male with definitive IE based on Duke criteria who experienced neurological complications of intracerebral bleeding. Patient was given pharmacological treatment according to the guidelines of the American Heart Association (AHA)with improvement in clinical symptoms.
\end{abstract}

Keywords: Infective endocarditis, intracerebral hemorrhage, septic embolism

\section{ABSTRAK}

Endokarditis infektif (EI) merupakan penyakit yang mengancam nyawa, walaupun angka kejadiannya kecil, yaitu 1,7-6,2 per 100.000 individu per tahun di negara berkembang. EI juga sangat potensial menyebabkan embolisasi, khususnya emboli septik ke otak. Emboli ini mengakibatkan manifestasi gangguan neurologis yang disebabkan karena oklusi pembuluh pembentukan dan ruptur aneurisma. Dilaporkan kasus seorang laki-laki 34 tahun dengan EI definitif berdasarkan kriteria Duke yang mengalami komplikasi neurologis perdarahan intraserebral. Pasien ditatalaksana sesuai panduan American Heart Association (AHA) dengan perbaikan gejala klinis.

Kata kunci: Endokarditis infektif, emboli septik, perdarahan intrakranial

*Departemen Neurologi FK Universitas Indonesia/RSUPN Dr. Cipto Mangunkusumo, Jakarta. Korespondensi: mkurniawan.md@ gmail.com.

\section{PENDAHULUAN}

Endokarditis infektif (EI) merupakan penyakit infeksi mematikan yang jarang terjadi dengan angka kejadian per tahun berkisar antara 1,7-6,2 per 100.000 orang. Di negara berkembang, insidensinya dua kali lebih banyak pada laki-laki dibandingkan perempuan.Meskipun jarang, EI merupakan kondisi dengan angka kesakitan dan angka kematian yang tinggi. Saat ini EI merupakan penyebab kematian ke-4 akibat infeksi setelah sepsis, pneumonia, dan abses intraabdomen. ${ }^{1}$ Berdasarkan International Collaboration on Endocarditis, penyebab EI paling banyak di seluruh dunia adalah Staphylococcus aureus. ${ }^{1-3}$

EI dapat mengakibatkan berbagai komplikasi organ, termasuk komplikasi ke otak. Komplikasi neurologis merupakan komplikasi ekstra-kardiak yang paling sering, sebanyak $25-27 \%$ dari seluruh kasus. Komplikasi ini umumnya mengancam nyawa dan seringkali terlambat diketahui karena tidak memiliki manifestasi klinis yang khas. Manifestasi klinis komplikasi neurologi pada EI dapat berupa infeksi, namun yang lebih sering berupa gangguan vaskular, yaitu stroke, baik iskemik maupun hemoragik. ${ }^{4-6}$

Komplikasi neurologis dapat terjadi sebelum atau saat EI didiagnosis, atau bahkan saat pemberian terapi. Pemeriksaan Computed Tomography (CT) scan kepala harus segera dilakukan terhadap kecurigaan keterlibatan neurologi. Jika memungkinkan, dilakukan pemeriksaan magnetic resonance imaging (MRI), karena memiliki sensitivitas yang lebih baik, termasuk dapat mendeteksi perdarahan mikro pada kasus asimtomatik. ${ }^{1-2}$

Meskipun amat jarang dijumpai, angka kejadian perdarahan intraserebral pada kasus ini dapat mencapai 5\%. Selain gejala peningkatan tekanan intrakranial yang merupakan gejala umum pada stroke hemoragik, ciri khusus perdarahan intraserebral pada endokarditis infektif berlokasi di daerah lobar, terjadi 
pada pasien usia muda, dan memiliki riwayat demam atau terdiagnosis endokarditis. ${ }^{7-8}$

\section{KASUS}

Pasien laki-laki berusia 34 tahun datang ke Instalasi Gawat Darurat (IGD) RSUPN Dr. Cipto Mangunkusumo (RSCM), Jakarta, diantar keluarga dengan keluhan penurunan kesadaran pada 3 hari sebelum masuk RS.

Lima bulan sebelumnya pasien mengalami nyeri kepala mendadak, dilakukan CT scan kepala dikatakan mengalami stroke hemoragik. Setelah itu pasien dapat beraktivitas biasa, namun merasa mudah lupa.

Tiga minggu sebelum masuk RS,pasien tibatiba mengalami kelemahan sisi tubuh sebelah kiri. Keluhan disertai mulut mencong ke kiri, bicara terdengar cadel, serta rasa baal pada sisi tubuh sebelah kiri. Tiga hari kemudian, pasien mengalami kejang berulang berupa jari tangan kiri bergerakgerak diikuti kelojotan seluruh tubuh, dan mulut tertarik ke sisi kiri.Pasien tidak sadar selama kejang dengan durasi sekitar 3 menit. Pasien dirawat dan dilakukan pemeriksaan CT scan kepala dikatakan mengalami perdarahan otak.

Tiga hari sebelum masuk RS, pasien mengeluh nyeri hampir di seluruh bagian kepala, muntah, diikuti penurunan kesadaran. Pasien dilakukan evaluasi CT scan ulang, tidak didapatkan perdarahan baru, sehingga pasien dirujuk ke RSCM.

Pasien atau keluarga tidak mempunyai riwayat hipertensi, diabetes, penyakit jantung, maupun penyakit paru sebelumnya, termasuk riwayat penggunaan obat-obat suntik mapun seks bebas.

Pemeriksaan fisik di IGD didapatkantekanan darah $110 / 70 \mathrm{mmHg}$, nadi 120 kali per menit, laju napas 16 kali per menit, suhu $37,1^{\circ} \mathrm{C}$, dan terdapat murmur pada auskultasi jantung. Pada pemeriksaan neurologisberupa skala koma Glasgow E4M6V5, paresis N.VII dan XII sinistra sentral, hemiparesis sinistra dengan kekuatan motorik 4, dan hemihipestesi sinistra. Pemeriksaan funduskopi mata kanan dan kiri didapatkan kesan normofundus, skor National Institutes of Health Stroke Scale (NIHSS) 6, lain-lain dalam batas normal.
Pasien didiagnosis sebagai epilepsi simptomatik bangkitan secondary generalized seizure, paresis N.VII dan XII sinistra sentral, serta hemiparesis dan hemihipestesi sinistra ec stroke hemoragik berulang suspek rupturaneurisma dan dicurigai adanya kelainan pada jantung.

Hasil pemeriksaan darah didapatkan penurunan kadar hemoglobin ( $\mathrm{Hb}$ 10,3gr/dl), leukositosis $12.400 / \mu \mathrm{L}$, peningkatan ringan pada SGOT dan SGPT $(47 \mathrm{u} / \mathrm{L}$ dan $77 \mathrm{u} / \mathrm{L})$, peningkatan CRP $9 \mathrm{mg} / \mathrm{L}$, dan tes ANA positif. Pada EKG didapatkan didapatkan sinus rhythm, normoaksis, HR 75x/menit, aksis normal, QRS sempit, $P$ wave normal, $P R$ interval 0,12 detik, ST changes (-), T inverted di V1-V4.Foto toraks menunjukkan kardiomegali dengan tanda awal bendungan paru (Gambar 1).

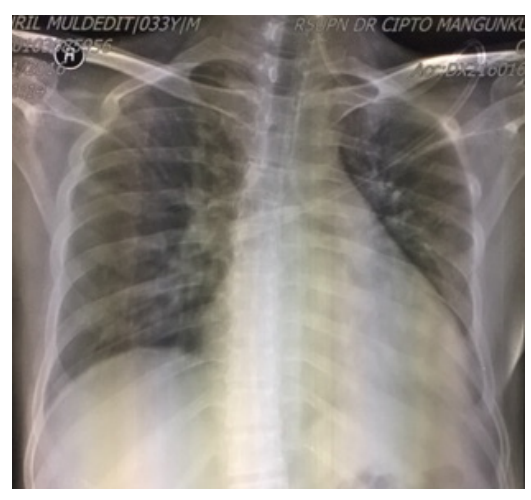

Gambar 1. Foto Toraks

Selama perawatan pasien diberikan infus RL 500cc/6 jam intravena, levetiracetam $2 \times 500 \mathrm{mg}$ per oral, paracetamol $3 \times 1$ gram intravena, asam folat $2 \times 5 \mathrm{mg}$ per oral, vitamin B6-B12 per oral, dan nimodipin $6 \times 30 \mathrm{mg}$ per oral. Pasien dikonsulkan ke Kardiologi, didiagnosis sebagai endokarditis infektif, diberikan terapi Ceftriaxone $1 \mathrm{x} 2 \mathrm{gr}$ iv dan Gentamycin 2x40mg iv.

Hasil pemeriksaan biakan darah berupa isolat coccus gram (+) yaitu Streptococcus alfahemolytic. Pasien dikonsulkan ke Divisi Tropik Infeksi, Gigi Mulut, dan THT untuk eksplorasi faktor risiko infeksi. Didapatkan gangren radiks pada gigi 4, 6 , 24, dan 25 sehingga dilakukan tindakan scaling dan ekstraksi gigi.

Pemeriksaan echocardiography menunjukkan adanya dilatasi atrium kanan dan kiri, tidak ada 


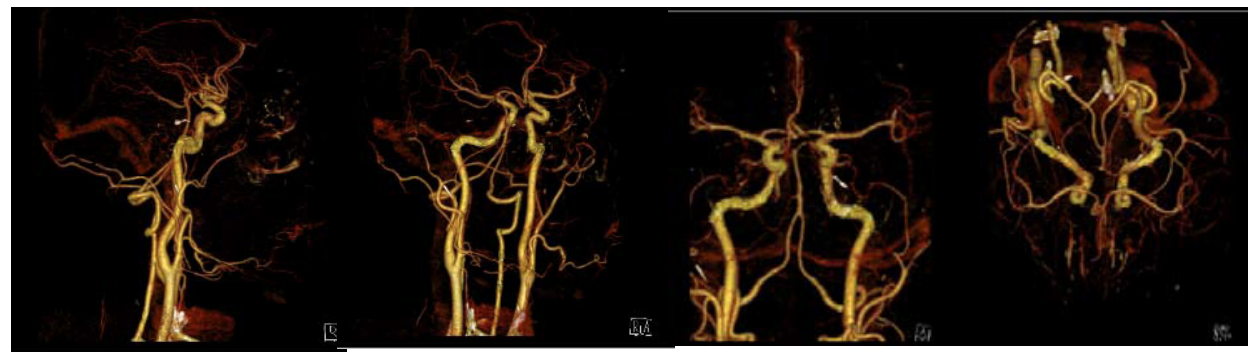

Gambar 2. Hasil CT Angiografi dengan Kontras

penebalanventrikel kiri, motion normal, regurgitasi mitral berat, prolaps anterior mitral leaflet (AML), fungsi diastolik baik, ejection fraction $77,8 \%$, tidak ditemukan trombus, serta terdapat vegetasi besar di AML dengan ukuran $2,22 \mathrm{~cm}^{2}$ dan $0,76 \mathrm{~cm}^{2}$.

Pemeriksaan CT angiografi didapatkan lesi hiperdens regio parietal dekstra dengan sebagian telah hipodens disertai dengan perifokal edema, taksiran volume $\pm 2 \mathrm{cc}$. Tidak tampak pergeseran garis tengah, aneurisma, maupun kelainan vaskular lain. Pasien dilakukan evaluasi ulang CT kepala tanpa kontras, didapatkan adanya perdarahan intraparenkim di lobus parietal kanan dengan perifokal edema dan pelebaran fokal sulci di regio frontal kanan.

Selama perawatan, kondisi umum pasien terpantau baik dan stabil. Status neurologis juga mengalami perbaikan, yaitu kekuatan motorik ekstremitas kiri atas dan bawah adalah $4+$. Terapi awal tetap dilanjutkan dan antibiotik diberikan hingga 4-6 minggu. Pasien dilakukan tindakan operatif kardiologi, yaitu mitral valve repair dengan ring annuloplasty, neochordae dan posterior leaflet augmentation, serta cardiopulmonarybypass. Pasien selanjutnya rawat jalan dengan NIHSS 4 dan skor modified Rankin Scale (mRS) 3.

\section{PEMBAHASAN}

Komplikasi neurologi pada EI merupakan kasus yang mengancam nyawa dan merupakan komplikasi ekstra kardial yang paling sering terjadi, dengan angka kejadian berkisar antara 25-75\% kasus. ${ }^{1,3-4}$ Beberapa prediktor terjadinya komplikasi neurologi ini antara lain ukuran vegetasi, lokasi vegetasi, dan lamanya pengobatan EI..$^{5-6}$ Komplikasi neurologi yang terjadi antara lain stroke iskemik, stroke hemoragik, aneurisma intrakranial infektif, meningitis, abses, dan ensefalopati dengan gambaran klinis yang amat bervariasi seperti penurunan kesadaran, nyeri kepala, gangguan nervus kranialis, kelemahan motorik, hingga kejang. ${ }^{1-2}$ Pada sebagian besar kasus, gejala neurologi terjadi sebelum atau saat EI didiagnosis, pada waktu pasien belum mendapatkan terapi antibiotik. ${ }^{2,8}$

Perdarahan intraserebral sebagai salah satu komplikasi neurologi pada kasus EI dipostulasikan dapat terjadi karena 3 mekanisme, yaitu 1) emboli steril akibat EI mengakibatkan infark yang kemudian mengalami transformasi hemoragik, biasanya memiliki gejala ringan dan asimptomatik bila pasien tidak mendapatkan terapi antikoagulan; 2) emboli septik selama infeksi yang belum terkontrol, umumnya akibat organismen yang virulen, menyebabkan arteritis akut dan erosif dan mengakibatkan ruptur pembuluh darah intrakranial; dan 3) emboli septik selama pemberian terapi antibiotik dan/atau berhubungan dengan organisme nonvirulen dapat menimbulkan injury pada dinding arteri sehingga mengakibatkan munculnya aneurisma subakut yang umumnya aseptik pada saat ruptur. ${ }^{7-8}$

Aneurisma intrakranial pada EI merupakan kondisi yang jarang terjadi, yaitu $2-4 \%$ pasien EI dan $5-12 \%$ pada pasien EI dengan komplikasi neurologis. Aneurisma pada EI dikenal sebagai aneurisma intrakranial infektif (terminologi lama menggunakan istilah aneurisma mikotik). Aneurisma tersebut terjadi akibat vegetasi jantung yang terlepas, kemudian sebagai materi emboli septik mengenai pembuluh darah intrakranial, baik pada percabangan ataupun bagian distal. Teori vasa vasorum menyebutkan bahwa mikroorganisme yang berasal dari emboli septik masuk melalui vasa vasorum dan menyebabkan inflamasi hebat pada tunika adventisia. 
Pulsasi arteri pada dinding pembuluh darah yang mengalami inflamasi ini menyebabkan pembentukan aneurisma. ${ }^{3,9-10}$

Ruptur aneurisma intrakranial infektif dapat bermanifestasi sebagai nyeri kepala, kejang, gangguan keseimbangan, dan defisit neurologi fokal yang sebagian ada pada pasien ini. Aneurisma yang ruptur seringkali tidak lagi terdeteksi pada pemeriksaan angiografi, sehingga hanya $1,7 \%$ kasus perdarahan intraserebral pada EI yang dilaporkan benar-benar terbukti disebabkan karena aneurisma yang pecah..$^{7-8}$

Pada kasus ini, pasien mengalami defisit neurologi berulang berupa riwayat penurunan kesadaran dan kelemahan mendadak sisi tubuh sebelah kiri. Dari pemeriksaan penunjang didapatkan perdarahan intraserebral. Perdarahan intraserebral diduga berhubungan dengan EI karena lokasi perdarahan di kortikal (perdarahan lobar), pasien berusia muda tanpa faktor risiko kardiovaskular klasik seperti hipertensi dan diabetes, serta diduga secara klinis menderita endocarditis infektif. terdapat 2 kriteria mayor, atau 1 kriteria mayor +3 kriteria minor, atau terdapat 5 kriteria minor.

Pasien memiliki underlying disease EI definitive yang ditegakkan berdasarkan kriteria Duke, didapatkan 3 kriteria mayor: biakan darah positif adanya mikroorganisme Streptococcus alfahemolytic, adanya gambaran vegetasi besar dan regurgitasi katup (katup mitral) pada pemeriksaan ekokardiografi. Selain itu terdapat beberapa kriteria minor yang positif, yakni kelainan jantung dan adanya fenomena vaskular berupa stroke.

Staphylococcus aureus adalah mikroorganisme virulen yang paling sering mengakibatkan perdarahan intraserebral simptomatik (53\%) yang terjadi pada fase awal penyakit saat infeksi belum terkontrol. Organisme lain yang berhubungan dengan perdarahan intraserebral pada EI adalah Streptococcus spp (18\%) dan Staphylococcus epidermidis (12\%). ${ }^{8}$ Pada kasus ini mikroorganisme yang ditemukan adalah jenis Streptococcus, hal ini sesuai dengan literatur dimana perdarahan intraserebral yang terjadi tidak seperti pada kasus

Tabel 1. Penegakan Diagnosis EI dengan Kriteria Duke pada Pasien

\begin{tabular}{lc}
\hline \multicolumn{1}{c}{ Kriteria } & Kasus Ini \\
\hline $\begin{array}{l}\text { Kriteria Mayor } \\
\text { - Biakan darah positif }\end{array}$ & $\begin{array}{c}\text { S. alfahemolyticus } \\
\text { Vegetasi besar } \\
\text { - Temuan ekokardiografik }\end{array}$ \\
- Regurgitasi katup baru & MR \\
Kriteria Minor & $\sqrt{ }$ \\
- Kelainan jantung atau pemakai obat intra-vena & - \\
- Demam & $\sqrt{ }$ \\
- Lesi vaskular & NR \\
- Fenomena imunologik & $\sqrt{ }$ \\
- Bukti mikrobiologik & $\sqrt{ }$ \\
Kesimpulan & EI Definitif \\
\hline
\end{tabular}

EI ditegakkan berdasarkan Kriteria Duke (Tabel 1) yang mengombinasikan gambaran klinis, mikrobiologi, patologi, dan ekokardiografi. Kriteria mayor EI meliputi hasil kultur darah dan gambaran ekokardiografi. Adapun kriteria minor berupa adanya predisposisi penyakit jantung, riwayat penyalahgunaan obat secara intravena, demam $>38^{\circ} \mathrm{C}$, adanya fenomena vaskular atau imunologi. Pasien didiagnosis sebagai EI definitif bila setidaknya yang disebabkan karena Staphylococcus aureus yang terjadi lebih awal dan memiliki gejala berat dengan prognosis buruk..$^{7-8}$

Terapi antibiotik adalah terapi utama pada EIuntuk menghilangkan sumber infeksi dan sterilisasi vegetasi katup. Lama pemberian antibiotik harus adekuat untuk memastikan eradikasi mikroorganisme. Terapi dapat diberikan lebih panjang bila menggunakan antibiotik bakterisidal kerja 
lambat. ${ }^{2}$ Pada sebagian besar kasus, terapi antibiotik untuk EI adalah terapi empiris. American Heart Association (AHA) merekomendasikan pemberian antibiotik kombinasi golongan betalaktam selama 4 minggu dan aminoglikosida selama 2 minggu. ${ }^{1-2}$

Pada pasien EI dengan perdarahan intraserebral, pemberian antiplatelet dan antikoagulan harus dihindari. Khusus bagi pasien katup jantung prostetik dengan EI dan perdarahan intraserebral, pemberian antikoagulan profilaksis dapat tetap diberikan, namun antikoagulan oral harus diganti dengan heparin intravena dan dipantau secara ketat. Bila perdarah makin bertambah, maka heparin dihentikan selama 10-14 hari. ${ }^{3}$

Pada kasus ini mendapatkan terapi antibiotik empirik berupa Ceftriaxone 1x2gr iv dan Gentamycin $2 \times 40 \mathrm{mg}$ iv untuk tata laksana EI. Terapi ini dinilai adekuat berdasarkan tidak adanya lagi gambaran aneurisma pada CT angiogram serebral yang dilakukan 1 bulan pascapemberian antibiotik.

Tindakan pembedahan (operasi katup jantung) adalah tindakan yang penting pada untuk memperbaiki kondisi jantung pasien. Tindakan operatif setelah stroke iskemik bukanlah suatu kontraindikasi, kecuali dipertimbangkan bahwa prognosis neurologis pasien sangat buruk. Pada pasien EI dengan perdarahan intraserebral, bila perdarahan telah dieksklusi melalui CT scan kepala dan tidak terdapat defisit neurologi berat seperti koma, tindakan operatif sebaiknya tidak ditunda. Namun bila terdapat perdarahan intrakranial yang signifikan, tindakan operatif dapat ditunda setidaknya 4 minggu setelah onset perdarahan intraserebral. ${ }^{3,11}$

Pada kasus ini, tindakan operasi jantung dilakukan 2 bulan setelah onset perdarahan intraserebral dengan kondisi hemodinamik dan neurologis telah stabil. Setelah tindakan perawatan pascaoperasi, pasien dipulangkan dengan dalam kondisi perbaikan dengan skor NIHSS 4 dan skor mRS 2. Pasien menjalani pengobatan rawat jalan dan saat dilakukan pemantauan 1 bulan setelah perawatan, kondisi pasien membaik dengan NIHSS 2 dan skor mRS 2. Enam bulan pascaperawatan, pasien telah dapat bekerja kembali dengan skor mRS 1 .
Prognosis pada pasien ini sesuai dengan studi bahwa prognosis EI dengan perdarahan intraserebral tergantung pada 2 hal, yakni mekanisme perdarahan dan tata laksana yang diberikan. Pasien dengan perdarahan yang disebabkan aneurisma infektif memiliki prognosis lebih baik dibandingkan perdarahan intraserebral yang tidak jelas etiologinya. Tata laksana operasi jantung memberikan juga pengaruh yang besar terhadap prognosis. Pasien yang dilakukan operasi yang memiliki prognosis lebih baik dibandingkan pasien yang tidak dilakukan operasi. ${ }^{12}$

\section{KESIMPULAN}

Perdarahan intraserebral pada kasus ini terjadi karena emboli septik mengakibatkan injury pada dinding arteri sehingga menyebabkan timbulnya aneurisma yang rentan pecah. Tata laksana spesifik pada EI dengan komplikasi neurologis adalah pemberian antibiotik. Tindakan pembedahan (operasi katup jantung) adalah tindakan yang penting.Pada EI dengan perdarahan intraserebral, tindakan bedah sebaiknya ditunda minimal 1 bulan setelah awitan dan dapat memberikan prognosis dan luaran yang baik.

\section{DAFTAR PUSTAKA}

1. Baddour LM, Wilson WR, Bayer AS, Fowler VG, Tleyjeh IM, Rybak MJ, dkk. Infective endocarditis in adults: diagnosis, antimicrobial therapy, and management of complications. AHA Scientific Statement. 2015;132:1-52.

2. The Task Force for the Management of Infective Endocarditis of the European Society of Cardiology (ESC). 2015 ESC Guidelines for the Management of Infective Endocarditis. European Heart J. 2015:36:154.

3. Morris NA, Matiello M, Lyons JL, Samuels MA. Neurologic complications in infective endocarditis: identification, management and impact on cardiac surgery. Neurohospitalist. 2015;4(4):13-222.

4. Setiawan M. Tinjauan pustaka: komplikasi neurologis endokarditis infektif. CDK. 2015;42(5):350-5.

5. Firsttenberg MS. Septic embolism: a potentially devastating complication of infective endocarditis in contemporary challenges in endocarditis. InTech. 2016.

6. Thiene G, Basso C. Pathology and pathogenesis of infective endocarditis in native heart valves. Cardiovasc Pathol. 2006;15(5):256-63.

7. Aziz F, Perwaiz S, Penupolu S, Doddi S, Gongireddy S. J Thorac Dis. 2011;3:134-7. 
8. Hart RG, Kagan-Hallet K, Joerns S. Mechanism of intracranial hemorrhage in infective endocarditis. Stroke. 1987;18:1048-1056.

9. Shu LM, Chung CN, Ming LT. New advances in the diagnosis and management of cardioembolic stroke. Acta Cardiol Sin. 2015;21:1-12.

10. Grecu N, Tiu C, Terecoasa E, Bajenaru O. Endocarditis and stroke. Maedica. 2014;9(4):75-381.

11. Benyounes N, Blanc R, Wellschbillig S, Obadia M, Chevalier G, Cohen A. A cardioembolic stroke. World J Cardiovasc Dis. 2014;4:9-13.
12. Sonneville R, Mourvillier B, Bouadma L, Wolff M. Management of neurological complications of infective endocarditis in ICU patients. Annals of Intensive Care. 2011;1(10):1-8.

13. Behrouz R. Reviews: preoperative cerebrovascular evaluation in patients with infective endocarditis. Clin Cardiol. 2015;38(7):439-42.

14. Salaun E, Touil A, Hubert S, Casalta JP, Gouriet $\mathrm{F}$, Robinet-Borgomano E, dkk. Intracranial hemorrhage in infective endocarditis. Arch Cardiovasc Dis. 2018;111(12):712-72. 